\title{
A Comparison of Service Quality in Teaching and Non-teaching Hospitals: The Gap Analysis
}

\author{
Rouhollah Zaboli' 'Mohammad Reza Soltani Zarandi ${ }^{2 *}$, Ali Ayoubian ${ }^{3}$ \\ 1. Health Management Research Centre, Baqiyatallah University of Medical Sciences, Tehran, Iran \\ 2. Department of Health Services Administration, Health School, Baqiyatallah University of Medical Sciences, Tehran, Iran \\ 3. Health Research Center, Baqiyatallah University of Medical Sciences, Tehran, Iran
}

*Corresponding Author: Mohammad Reza Soltani Zarandi, M.Sc Student, Department of Health Services Administration, Health School, Baqiyatallah University of Medical Sciences, Tehran, Iran

Email: soltanizarandi@gmail.com

\begin{abstract}
Introduction: Service quality is a judgment that the customer compares his/her expectations by this judgment, with the perception of the received services. The purpose of this study was to compare service quality in teaching hospitals with non-teaching hospitals in Kerman city.

Methods: This cross-sectional study has been done on 166 hospitalized patients and the standard SERVQUAL questionnaire with an approved validity and reliability was used. Data analysis was performed using SPSS software version 19.

Results: The results show that the service quality from the patients' perception in non-teaching hospitals is more than the teaching hospitals $(\mathrm{p}=0.002)$. Most of the service quality gap is in the tangibility dimensions and also in providing amenities for patients and their companions.

Conclusion: Teaching setting of the hospital typically can cause poor subjectivity in patients about the quality of services provided and it is recommended that authorities identify factors causing these kind of thinking and solve them. Also the negative scores indicate a need for improvement in all aspects, especially the tangibility dimensions having the maximum gap.
\end{abstract}

Keywords: Patient Expectations, Service Quality, Teaching Hospital, SERVQUAL

Article History: Received: 2 Jul 2014; Revised: 25 Jul 2014; Accepted: 1 Aug 2014

Cite this article as: Zaboli R, Soltani Zarandi MR, Ayoubian A. A comparison of service quality in teaching and non-teaching hospitals: The gap analysis. Int J Travel Med Glob Health. 2015;3(1):37-42.

\section{Introduction}

The importance of service quality in organizations dealing with a high volume of customers is rapidly growing [1]. The effectiveness of large investments of organizations could be wiped out due to poor service quality [2]. Service quality is an important factor in the growth, success and survival of organizations [3]. As the service quality has different meanings for different people therefore we must first have a clear understanding of the term quality [4].

Quality is defined as purity of contents in the dictionary and is considered as the amount of meeting customer's needs to services or products [5-10]. Quality often means continuous improvement of processes and further improvement as a process of setting standards, measuring and creating evolution [11]. Service quality is a young field that has been studied on for the past two decades [12]. It is also considered as a judgment that the customer compares his/her expectations by this judgment, with the perception of the received services [13].

Absence of communication with the customer causes a difference between his/her expectations and the perception of the ideal situation [14]. Care quality is the degree of appropriateness of health care providers' function that may satisfy the service recipients [15]. The evaluation of customer perception is one of the most important topics in the field of service quality $[15,16]$. This has caused the American's National Organization of health services makes all the providers in set their plans [17].

Providing care services in accordance with the patients' needs and expectations can lead to an improvement in the quality of hospital services [18]. America spent more than two trillion dollars on health care in 2006 , while only $44 \%$ of respondents were satisfied with the quality of health services. Hospitals are the most important element of health care and about $50 \%$ of health care expenditure is used in this area [15]. The quality of healthcare has two dimensions. Technical (accuracy of medical diagnoses and procedures) and functional (process by which health care is provided) and the patients often establish the quality of services provided in hospital based on their understanding of health care services [19-21]. However, the patients' perception of their care, particularly in hospitals is poorly understood [17, 22, 23].

According to Hesket, more perceived value by the health care customers makes customers want to reuse hospital services in the future [16]. Johansson et al. believe that patient satisfaction should be expressed by themselves [24]. Babakus and Boller believe that it is the customer not the provider that should determine the most useful aspects of services [25]. Various studies in Iran and the world show that neither the public nor the private hospitals have been able to meet the patients' needs [26]. 


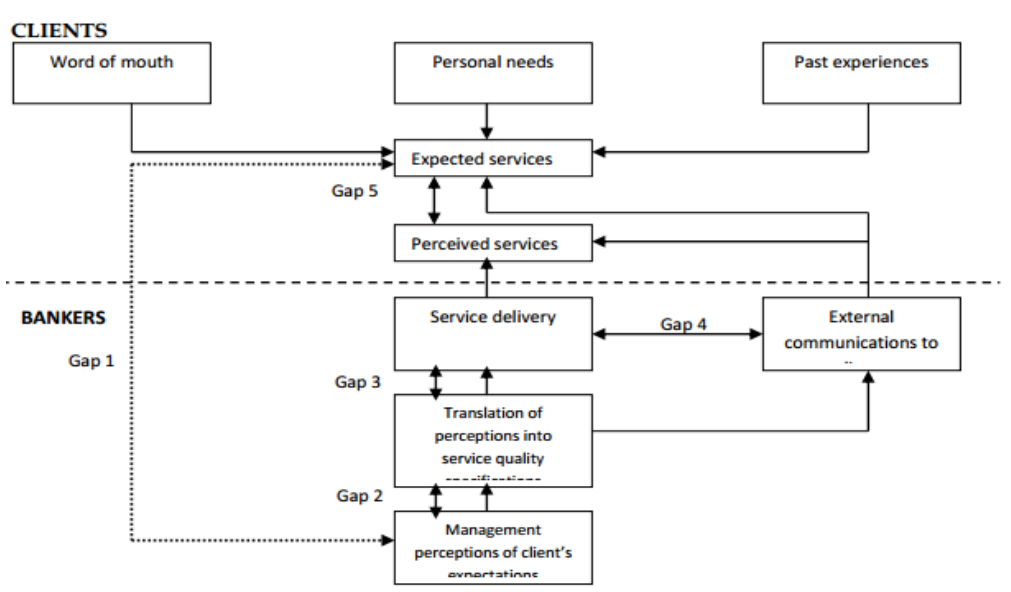

Figure 1. Conceptual model of service quality (Parasuraman et al., 1985)

According to researches done by us, the comparative research of the perceived quality by patients hasn't been conducted between teaching and non-teaching hospitals of Kerman before this study. So the aim of this study is to evaluate the patients' perception of services at teaching hospitals compared to non-teaching hospitals. While the general patients' perception of Kerman hospitals will be finally analyzed.

\section{Methods}

This cross-sectional study was conducted in the summer 2014 in Kerman. All of the hospital affiliated to the Kerman University of medical sciences comprised the population of this study. The sample size was estimated with the Cronbach's alpha formula. According to the formula of estimating the sample size, number 77 and with a probability of $10 \%$ attrition, number 86 was obtained [27]. Therefore, 86 patients at teaching hospitals and 86 patients at non-teaching hospitals were selected for the study. The number of selected patients from each hospital has been estimated based on the number of active beds per hospital. SERVQUAL standardized questionnaire were used in this study. This tool has been developed by Parasuraman et al with regards to the five dimensions of service quality including tangibility, reliability or validity, responsiveness, assurance and empathy. SERVQUAL is a standard reliable and valid tool for measuring the quality in hospital environments [28].

Gathering data and information required in the study was done through a three-part questionnaire. The first section includes questions related to consumers' individual demographic characteristics and the second and third sections includes the SERVQUAL instrument to measure the perceptions and expectations of the care quality provided. A 5 point Likert-type response options have been considered. Option 5 means I quite agree and option 1 is totally disagree. Ultimately the different scores between each question of the perception were calculated in accordance with the question of expectation and the score obtained from this difference was considered as the score of the service quality gap. For those illiterate, uneducated, powerless and similar cases, the questionnaire was completed by their companions. At least 24 hours of hospitalization, and age over 15 years were the inclusion criteria. Outpatients and unconscious patients were excluded from the study .

The number of inpatients in any ward at the time of reference was the basis of selecting the patients in each hospital. Among the 86 questionnaires distributed in teaching hospitals, 81 questionnaires (the response rate: $94.1 \%$ ) and of the 86 questionnaires distributed in non-teaching hospitals, 85 questionnaires (the response rate: $98.8 \%$ ) were fully completed and collected.

Data analysis was conducted using the SPSS software version 19 and using descriptive statistical methods and absolute frequency, mean and standard deviation of quality score was calculated. The T-test was used for data analysis and to compare the mean score of expectations, perceptions and service quality and the Spearman correlation coefficient, Pearson, chi- square or Fisher tests were used for evaluating the relationship between different variables based on the type of qualitative and quantitative variables.

\section{Results}

A total of 166 patients, among which 93 patients were male $(56 \%)$ and 73 patients were female (44\%) were studied. 58 patients (34.9\%) aged 15 to 30 years , 36 patients $(21.7 \%)$ aged 31 to 45 years , 29 patients (17.5\%) aged 46 to 60 years and 43 patients (25.9\%) were over 60 years old. 87 patients (52.4\%) were low-literate, 57 patients $(34.3 \%)$ had the document of diploma and advanced diploma, 22 patients (33.3\%) had a Bachelor's degree and a master's degree and there were no cases with a $\mathrm{PhD}$ degree. 90 patients (54.2\%) were experiencing the first admission in the hospital where the questionnaire was being completed. 20 patients (20\%) had a history of one time hospitalization and 56 patients (33.7\%) had a history of more than one admission to that hospital (Table 1).

If we dedicate the phrases bad, poor, fair, good and excellent to the scores of the questionnaire respectively one to five, we find that the average patients' perception of service quality in both teaching and non-teaching hospitals of Kerman is higher than average, but the quality from patients' perception in non-teaching hospitals is more than teaching hospitals and this difference is statistically significant $(\mathrm{p}<0.001)$ (Table 2). 
Table 1. Demographic data of patient

\begin{tabular}{|c|c|c|c|c|}
\hline \multirow{2}{*}{\multicolumn{2}{|c|}{ Demographical Variable }} & \multicolumn{2}{|c|}{ Hospital Affiliation } & \multirow{2}{*}{$\begin{array}{l}\text { Total } \\
f(\%)\end{array}$} \\
\hline & & Teaching & Non-teaching & \\
\hline \multirow{2}{*}{ Sex group } & Male & $48(51.6)$ & $45(48.4)$ & $93(100)$ \\
\hline & Female & $33(45.2)$ & $40(54.8)$ & $73(100)$ \\
\hline \multirow{4}{*}{ Age group } & $15-30$ years & $25(43.1)$ & $33(56.9)$ & $58(100)$ \\
\hline & $30-40$ & $20(55.6)$ & $16(44.4)$ & $36(100)$ \\
\hline & $40-50$ & $16(55.2)$ & $13(44.8)$ & $29(100)$ \\
\hline & Up to 50 & $20(46.5)$ & $23(53.5)$ & $43(100)$ \\
\hline \multirow{3}{*}{ Education level } & Under graduate & $46(52.9)$ & $41(47.1)$ & $87(100)$ \\
\hline & Master graduate & $30(52.6)$ & $27(47.4)$ & $57(100)$ \\
\hline & Post graduate & $5(22.7)$ & $17(77.3)$ & $22(100)$ \\
\hline \multirow{3}{*}{ Number of refers } & $1^{\mathrm{st}}$ & $45(50)$ & $45(50)$ & $90(100)$ \\
\hline & $2^{\mathrm{st}}$ & $6(30)$ & $14(70)$ & $20(100)$ \\
\hline & More than $3^{\text {st }}$ & $30(53)$ & $26(46.4)$ & $56(100)$ \\
\hline
\end{tabular}

Table 2. Mean and standard deviation of perceptions, expectations and service quality gap

\begin{tabular}{llccc}
\hline & & Patients' Perception of Service Quality & Patients' Expectation of Service Quality & Service Quality Gap \\
\hline \multirow{2}{*}{ Teaching hospitals } & Mean & 3.66 & 4.73 & -1.07 \\
\multirow{2}{*}{ Non-teaching hospitals } & Standard deviation & 0.81 & 0.29 & 0.88 \\
& Mean & 4.01 & 4.62 & -0.61 \\
& Standard deviation & 0.59 & 0.37 & 0.68 \\
\hline
\end{tabular}

Table 3. Service quality gap in five dimensions:

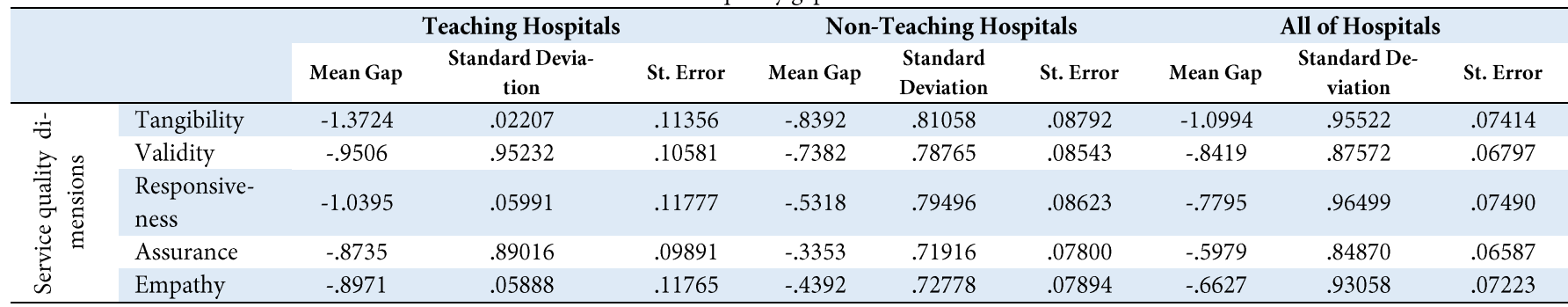

Patients' expectation of service quality in teaching hospitals is more than non-teaching hospitals and this difference is statistically significant $(\mathrm{p}<0.04)$ (Table 2$)$. Also the service quality gap from patients' perception in teaching hospitals is more than non-teaching hospitals and this difference is statistically significant $(\mathrm{p}<0.001)$ (Table 2$)$.

There is no significant relationship between sex, education and the number of previous references to the hospital with patients' perception of the quality but there is a weak and negative correlation between the age and perception of service quality $(-0.27)$ and is statistically significant $(\mathrm{p}=0.01)$. The relationship between the type of hospital and the possibility of further reference to it is statistically significant $(\mathrm{p}<0.001)$.

In all the five dimensions of the questionnaire, the findings showed that there is a gap between the patients' perceptions and expectations of service quality provided in Kerman teaching and non-teaching hospitals and all of these gaps were statistically significant $(\mathrm{p}<0.001)$ (Table 3$)$.

The gap score between patients' perceptions and expectations of service quality in all the hospitals of Kerman was negative in all dimensions and were statistically significant $(\mathrm{p}<0.001)$ (Table 3).

Reviewing all the questions asked in each of the five dimensions also shows that there was a gap in all items too and all the gaps were also statistically significant $(\mathrm{p}<0.001)$.
In the tangibility dimension, the maximum and minimum gap in teaching hospitals are respectively related to providing amenities for patients and their relatives $(-1.96)$ and clean and neat appearances of the staff (-0.64) and in nonteaching hospitals respectively to modern and updated equipment (-1.12) and providing services by employees in accordance with their professional obligations (-0.46) .

In the validity dimension, the maximum gap in both teaching and non-teaching hospitals is related to hospitals dealing with complaints or problems of patients (-1.23 and -1.02, respectively) and also the minimum gap in both is related to the protection and confidentiality of patients by hospitals and their staff ( -0.52 and -0.58 , respectively).

In the responsiveness dimension, the maximum gap in both teaching and non-teaching hospitals is related to the speed of the admission of patients ( -1.12 and -0.67 , respectively) but the minimum gap in teaching hospitals is related to the appropriate behavior of the staff and dealing with patients and establishing trust and confidence in them (-0.9) and in non-teaching hospitals is related to immediate access to staff when requested immediate assistance by the patients (-0.39). In the assurance dimension the maximum gap in teaching hospitals is related to the option that staff and physicians answer the patients' questions (-1.17) and in non-teaching hospitals is related to modest and friendly behavior with patients $(-0.43)$ while the minimum gap in both teaching and 
non-teaching hospitals is related to the privacy of patients by staff and physicians (-0.72 and -0.2 , respectively).

Finally in the empathy dimension, the maximum gap in both teaching and non-teaching hospitals is related to understanding the wants and needs of patients by physicians and staff and considering them (-1.02 and -0.53 , respectively ) while the minimum gap in teaching hospitals is related to physicians and staff empathy with patients and creating emotional connection with them (-0.83) and in non-teaching hospitals is related to physicians and staff respecting the patient s' cultural, beliefs and values by physicians and staff $(-0.27)$.

\section{Discussion}

Research findings indicate that although patients' perception of service quality in both teaching and non-teaching hospitals of Kerman is higher than average but the service quality from patients' perception in non-teaching hospitals is higher than teaching hospitals.

Secondly, despite higher than average perceived service quality, the average gap of service quality is negative in all the aspects and it is suggested that patients' expectations are higher than their perception from the current status and this result is consistent whit research results of Razlansari [8], Janaabadi [15], Hekmatpoo [25], Zarei [28], Sabahi [29] and many other domestic and foreign researches [1].

The maximum gap in the present research is related to the tangibility dimension in both teaching and non-teaching hospital that similar results were obtained in Janaabadi's studies [15].

Based on the results already mentioned, we can help to reduce this gap by providing amenities for patients and their relatives in teaching hospitals and improving facilities and providing modern diagnostic equipment's in non-teaching hospitals.

The smallest gap in both teaching and non-teaching hospitals is related to the assurance dimension and according to the data, we can offer solutions to reach excellent status, such as specifying locations in teaching hospitals in order to fully respond to all the patients' questions with scientific principles. It should be mentioned that the staff and physicians should the patients more modestly and friendly in nonteaching hospitals.

Since the maximum gap in both teaching and non-teaching hospitals in the validity dimension is related to hospitals dealing with complaints or problems of patients, hospital managers should think of measures to better handle clients' complaints and defend the rights of patients consistently. Moreover, it must not violate and overwhelm the rights of others especially the staff and physicians. Given that the minimum gap in this dimension in both types of hospitals is related to the protection and confidentiality of patients by hospitals and their staff, it seems that the ministry must identify ways to achieve this success and offer them to other centers which are poor in this dimension.
Since the maximum gap in both teaching and non-teaching hospitals in the responsiveness dimension is related to speed at admission of patients, it seems that the authorities should identify barriers to timely admission of patients including lengthy processes of documentation and registration of primary data and eliminate these barriers or postpone some stages after hospitalization to reduce this gap.

According to estimates in the empathy dimension, the maximum gap in both teaching and non-teaching hospitals is related to understanding the wants and needs of patients by the physicians and staff and paying attention to them (-0.77). Further research must be done to specify ways of better understanding the wants and needs of patients and put them as priority to take this gap to the optimum.

In this research, by evaluating the non-comparative aspect of various dimensions of quality gap in teaching and nonteaching hospitals of Kerman, we realize that the maximum gap is related to the tangibility dimension which is consistent with the results of Sabahi [42] and the minimum gap is related to the assurance dimension (-0.6. The dimensions validity' responsiveness and empathy are between these two dimensions respectively with the total average of $-0.846-0.78$ and -0.66 .

In the tangibility dimension, the maximum and minimum gap was estimated to be respectively related to providing amenities for patients and their relatives (-1.51) and clean and neat appearances of staff $(-0.6)$ which in comparison ، had the same results just in teaching hospitals. It seems that the authorities of teaching hospitals should consider this issue and try to reform these because they could direct the total average mean of data toward themselves.

In the validity dimension, the maximum and also the minimum gap in both teaching and non-teaching hospitals was the same which we've already reached the same results and discussed on it (the maximum gap is related to hospitals dealing with complaints or problems of patients (-1.12) and the minimum gap is related to the protection and confidentiality of patients by hospitals and their staff $(-0.6))$.

In the responsiveness dimension, the maximum gap is related to the speed of the admission of patients $(-0.89)$ that in comparison 'the same result was obtained and the analysis were performed. The minimum gap was related to immediate access to staff when requested immediate assistance by the patients $(-0.71)$ which is consistent with the results of Janaabadi [15].

In the assurance dimension, the maximum gap was related to answering the patients' questions by staff and physicians $(-0.75)$ which in comparison, the teaching hospitals had the same results that requires attention. The minimum gap was related to providing privacy of patients by the staff and physicians $(-0.45)$ that in comparison the same overall result was obtained and the necessary analysis was performed.

Ultimately in the empathy dimension, the maximum gap is related to understanding the wants and needs of patients by the physicians and staff and paying attention to them $(-0.77)$ 
which the same overall result was obtained previously. The smallest gap in this dimension is estimated to be related to respecting the patients' beliefs and cultural values by physicians and staff showing the promoting culture and beliefs of Kerman.

The overall estimation of the questionnaire regardless of comparisons, the maximum gap in the quality of provided services from patients' perception is related to providing amenities for patients and their companions by the hospital $(-1.51)$ and the minimum gap is related to providing privacy of patients' by the staff and physicians $(-0.45)$ which both of these cases have already been discussed and the necessary suggestions have been provided.

In addition to the other suggestions in this article rit is suggested that researches take concern and identify the fundamental and key factors influencing patients' perception of service quality to improve the current situation of hospitals by reducing and eliminating adverse factors and developing useful factors.

\section{Conclusions}

Since the patients' perception of service quality is higher in non-teaching hospitals than the teaching iit suggests that the title of hospital as teaching 'can somehow cause poor patients perception of quality of services provided that the authorities of these hospitals must take it into consideration ‘ identify the factors of this thinking and strive to meet them. Also the higher level of expectation in all patients than their perception of service quality in all hospitals indicates that the authorities should still try to improve the dimensions of quality especially the tangibility dimension (and particularly the provision of facilities for patients and their relatives) which has the largest gap.

\section{Acknowledgements}

The authors are thankful to the authorities and staff of hospitals.

\section{Authors' Contributions}

Authors contributed to the publication of this article as follows: study concept and design, analysis and interpretation of data by Rouhollah Zaboli; statistical analysis and critical revision of the manuscript by Soltani Zarandi and Ali Ayoubian.

\section{Funding/Support}

None declared.

\section{Financial Discloser}

The authors declared no financial support.

\section{References}

1. Punnakitikashem P, Buavaraporn N, Maluesri P, Leelartapin K, editors. Healthcare Service Quality: Case Example of a Hospital with Lean Implementation. POMS 23rd Annual Conference, Chicago, Illinois, USA, April; 2012.

2. Armstrong G, Cunningham MH, Kotler P. Principles of marketing, 10th Ed: Scarborough, Ont.: Prentice Hall; 2004.
3. Sahney S, Banwet D, Karunes S. An integrated framework for quality in education: Application of quality function deployment, interpretive structural modeling and path analysis. Total Quality Management \& Business Excellence. 2006;17(2):265-85.

4. Tabarsi G, Ahmadizad A. Evaluation of the quality of health care centers covered by the Foundation of Martyrs and Veterans Affairs of Tehran (Persian). Veteran Med J. 2011;3(2):5-40.

5. Soltani Zarandi M. Principles and Fundamentals of Medical Terminology. Tehran: Boshra and Tohfe; 2014.

6. Zarbaf M, Roshani Barab F. Developed a model for measuring customer satisfaction and its application in rubber industry. J Management. 2008;5(12):47-62. Persian

7. Gharibi F, Tabrizi J, Ramezani M, editors. Quality improvement of service provided to patients referred to physiotherapy clinics Rehabilitation, The first national congress of the student's clinical governance and continuous quality improvement, Tabriz university of medical sciences; 2012.

8. Razlansari M, Teymouri B, Alipour Shirsavar H, Taleqani M, Hoseyn A. Perceived service quality using SERVQUAL model of the patients hospitalized in teaching hospitals of Kermanshah University of Medical Sciences in 1391. J Clinical Res Paramedical Sci. 2013;3(3).

9. Bahadori M, Abdi B, Teimourzadeh E, Ayoubian A, Yaghoubi M. Assessment of quality transportation services at a military medical center based on SERVQUAL model. J Military Med. 2013;15(3):177-83

10. Emami Razavi S, Mohaqqeq MR, Karani H, Mahdavi S, Khalifegari S, et al. A look at the hospital accreditation standards. Tehran: SEDA Publication Center; 2000, 428-429. Persian

11. World Health Organization. Quality and accreditation in health care services: a global review. 2003.

12. Shi T, Gill R. Developing effective policies for the sustainable development of ecological agriculture in China: the case study of Jinan County with a systems dynamics model. Ecological Economics. 2005; 53(2):223-46.

13. Rust RT, Lemon KN, Zeithaml VA. Return on marketing: using customer equity to focus marketing strategy. J Marketing. 2004;68(1):109-27.

14. Aqamolayi T, Zare S, Kebryayi A, Pudat A. Quality of primary health care from the perspective of women referred to healthCare centers of Bandar Abbas. Payesh J. 2007;7(2):121-7. Persian

15. Janaabadi H, Ebili K, NastiZayi N, Yaqubi N. Interval between patients' perceptions and expectations of service quality of Zahedan health centers using SERVQUAL model. Payesh J. 2011;10(4):44957. Persian

16. Zarei E, Arab M, Rashidiyan A, Qazi Tabatabayi S, Rahimi Foroushani A. The relationship between the quality of the services provided and the perceived value by hospitalized patients. J Mazandaran Med University. 2011;22(98):105-12. Persian

17. Jafari F, Johari Z, Zayeri F, Ramezan Khani A, Iran ZS. Satisfaction survey and factors affecting it in patients' refering to health centers. J Shahed University. 2006;14(66). Persian

18. Pakdil F, Harwood TN. Patient satisfaction in a preoperative assessment clinic: an analysis using SERVQUAL dimensions. Total Quality Management \& Business Excellence. 2005;16(1):15-30.

19. Negarande R, Mohammadi S, Zabolipour S, Arazi Qajaq T. Evaluation of correlation between quality of caring behaviors of nursing students and the patient satisfaction. J Nurs Midwifery. 2011;18(3):10-21. Persian

20. Isaac T, Zaslavsky AM, Cleary PD, Landon BE. The Relationship between Patients' Perception of Care and Measures of Hospital Quality and Safety. Health Service Res. 2010;45(4):1024-40.

21. Lin H-C, Xirasagar S, Laditka JN. Patient perceptions of service quality in group versus solo practice clinics. Int J Quality Healthcare. 2004;16(6):437-45.

22. Han C-H, Connolly PM, Canham DE, RN, C. Measuring Patient Satisfaction as an Outcome of Nursing Care at a Teaching Hospital of Southern Taiwan. J Nurs Care Quality. 2003;18(2):143-50.

23. Ha AK, Orav EJ, Zheng J, Epstein AM. Patients' perception of hospital care in the United States. New England $J$ Med. 2008;359(18):1921-3

24. Joulayi S, Haji Babayi F, Jafar Jalal E, Bohrani N. Evaluation of patients' satisfaction with nursing care provided in medico teaching hospitals. J Nurs Midwifery. 2012;17(1): 35-44. Persian

25. Hekmatpoo D, Sourani M, Farazi A, Fallahi Z, Lashkar Ara B. Investigating the quality of health care in the hospitals of Arak University of Medical Sciences and Health Services Using SERVQUAL model in the year 1390. J Arak University Medi. 2011;15(7):1-9. Persian 
26. Tabibi S, Gohari M, Shahri S, Aqababa S. quality of services provided in outpatient clinics of Tehran Hospitals based on SERVQUAL Model. Journal of Faculty of Paramedical Sciences of Tehran University of Medical Sciences. 2012; 5(4):49-56. Persian

27. Mohammad K, Malekafzali H. STATISTICAL METHODS and health indicators. 14 ed. Tehran: Daricheno; 2010. Pp. 298. Persian 28. Zarei E, Qazi Tabatabayi S, Rahimi Foroushani A, Rashidiyan A,
Arab M. Evaluation of hospital service quality from patient's perspective: A cross-sectional study in Tehran private hospitals. Peyavard Salamat. 2011; 5(4):66-76. Persian

29. Sabahi Bidgoli M, Mousavi S, Kebryayi A, Sayyedi S, Shahri S, Mahmoud A. Assessment of the quality of health care services in the patients admitted to hospitals of Kashan University. Feyz J. 2011;15(2):146-52. Persian 